\title{
Valorização profissional sob a perspectiva dos policiais do Estado do Rio de Janeiro
}

\author{
Professional self-image from the perspective of police officers \\ of the State of Rio de Janeiro
}

Maria Cecília de Souza Minayo ${ }^{1}$

${ }^{1}$ Claves, Escola Nacional de Saúde Pública, Fundação Oswaldo Cruz. Av. Brasil 4036/700, Manguinhos. 21040-361 Rio de Janeiro

RJ.maminayo@terra.com.br

\begin{abstract}
This paper presents the viewpoint of civil and military police officers of the State of Rio de Janeiro on the issue of professional and human self-image. It adopts five qualitative indicators as parameter of analysis, namely dignity, achievement, recognition, security and promising prospects, drawn from the sociological theory of social roles and proposals for human resource management. From the methodological standpoint, the study provides a contextual analysis of texts written by these agents at the end of a closed questionnaire on work, health and life conditions, conducted in a series of studies that began in 2003 and provided material for two books about these categories. The analysis considered the relevance given by the authors themselves when they describe their situation, using the five indicators mentioned as parameters. The results of this study show that the two categories have serious problems with professional self-image, especially with regard to wages, housing conditions, access to health services and to institutional and psychological support.
\end{abstract}

Key words Occupational health, Professional selfimage, Psychological support, Institutional support
Resumo Este artigo apresenta a visão dos policiais civis e militares do Rio de Janeiro sobre o tema de valorização humana e profissional. A partir da teoria sociológica sobre papéis sociais e de propostas de administração de recursos humanos, o texto tem como parâmetro de análise cinco indicadores qualitativos de valorização: dignidade, realização, reconhecimento, segurança e perspectiva promissora. Do ponto de vista metodológico, o estudo constitui uma análise contextualizada de textos escritos por esses agentes, ao final de um questionário fechado sobre condições de trabalho, de saúde e de vida, realizados numa série de estudos que se iniciaram em 2003 e que vieram a ser material para dois livros sobre as categorias. Os depoimentos foram trabalhados a partir das relevâncias dadas por seus próprios autores, tendo como parâmetro os cinco indicadores citados. Os resultados do estudo mostram que as duas categorias têm sérios problemas de valorização profissional, principalmente quanto aos salários, às condições habitacionais, ao acesso a serviços de saúde e ao apoio institucional e psicológico.

Palavras-chave Saúde do trabalhador, Valorização profissional, Apoio psicológico, Apoio institucional 


\section{Introdução}

Este artigo trata do tema "valorização profissional" sob a perspectiva dos policiais do Estado do Rio de Janeiro. O termo valorização constitui uma noção imprecisa que serve para designar uma série de ideias no campo da administração de recursos humanos. Estudos acadêmicos também costumam discuti-lo sob a perspectiva do senso comum segundo o qual ser valorizado é ganhar mais e ter mais valor significa ter mais dinheiro.

Chama atenção na literatura, o fato de "valorização profissional" estar sempre referida a algumas profissões do setor de serviços como a de professor do ensino básico ${ }^{1}$; de enfermeiros ${ }^{2}$, altamente necessárias à sociedade, mas com pouca visibilidade e baixa remuneração. Alguns autores vêm aprofundando o setor de serviços e as especificidades das profissões que o compõem. Destaca-se a abordagem de Meirelles ${ }^{3}$, segundo a qual, (1) serviço é trabalho em processo; (2) é atividade de uso intensivo de recursos humanos, ainda que mediada por instrumentos; (3) é marcado por interatividade, exigindo sustentação de fluxo e de vínculo entre prestadores e usuários; (4) tem como resultado um produto intangível; (5) produção e consumo do serviço se dão de forma simultânea no tempo e no espaço; (6) a produção ocorre quando o serviço é demandado e se encerra quando a demanda é atendida; (7) não é possível armazenar um serviço para consumi-lo depois, pois ele se extingue logo que é prestado; (8) o atendimento direto e pessoal - diferente do trabalho industrial - dificulta a flexibilização das relações de trabalho e facilita privilégios e corrupção. Ora, se cada ação se esgota no momento em que é realizada, o planejamento no setor de serviços se torna uma questão central e deve, do ponto de vista institucional, prever o médio e o longo prazo mas também, a ação imediata: atos mal planejados ou mal executados, colocam a perder um sucessivo bom atendimento e podem influir na imagem de uma categoria ${ }^{4}$.

A literatura sociológica refere que valorização profissional está diretamente ligada ao papel social desenvolvido pelo sujeito por meio de modelos de comportamento, responsabilidades, expectativas e privilégios ${ }^{5}$ e associada à avaliação, por meio de um julgamento formado através de complexos filtros perceptivos: (1) características prévias sobre as pessoas ou grupos que desempenham determinado papel; (2) valores, expectativas, normas e convenções; (3) há casos (como o da polícia) em que o papel entranha tanto a identidade do profissional que chega a definir o que ele é, como age e o que pensa; (4) determinados papéis sociais proveem as pessoas com oportunidades que lhes propiciam positividade para o enfrentamento de dificuldades e problemas; (5) e, por fim, existe relação entre identificação e apreciação social do papel exercido: quanto mais os profissionais são percebidos positivamente pela sociedade e por sua instituição mais tendem a valorizar os papéis desempenhados, num movimento cumulativo entre reconhecimento e resiliência ${ }^{6-8}$.

Pelos pontos acima aventados, os estudos sobre conceito de valorização profissional ressaltam que o salário não pode ser tratado como objetivo, mas como consequência da gestão de pessoas. Ganhar mais não expressa, necessariamente, ser mais valorizado, pois lembra Gabrie$\mathrm{le}^{9}$ a satisfação e o prazer no trabalho estão ligados a temas tangíveis como remuneração e aspectos subjetivos, dentre os quais, respeito e confiança, ambiente institucional favorável, orgulho de fazer algo importante para si e para a sociedade e prazer de enfrentar e vencer desafios. Esse conjunto de fatores foram observados nos estudos sobre Policiais Civis $^{10}$ e Militares ${ }^{4,11}$ do Rio de Janeiro.

Padilha $^{12}$ apresenta cinco indicadores para fundamentar a noção que aqui se discute: dignidade, realização, reconhecimento, segurança e perspectiva promissora. Neste texto esses termos serão considerados categorias estruturantes da análise.

\section{Metodologia}

Várias pesquisas do Centro Latino Americano de Estudos sobre Violência e Saúde (CLAVES) com Policiais Civis e Militares do Rio de Janeiro tiveram como ponto de partida a aplicação de um questionário fechado, utilizado para compreender seu perfil, suas condições de trabalho, de saúde e de vida ${ }^{4,10}$. Foram 1120 os policiais militares que responderam a esses instrumentos num universo de 22.180 dos que trabalham na capital do Rio de Janeiro e cerca de 2600 de policiais civis no universo de 11.000 que servem tanto na região metropolitana, como no interior do Estado. Essas duas amostras passaram por uma técnica estatística de expansão, de forma a tornálas representativas ${ }^{4,10}$. Paralelamente ao estudo quantitativo, foram realizadas 61 entrevistas e grupos focais com Policiais Civis e 100 com Policiais Militares. Em toda a investigação, a ideia da "valorização profissional" esteve presente. Mas, 
além das estratégias metodológicas formais, ao final dos questionários, colocou-se um espaço aberto para que os respondentes, caso o desejassem, expressassem suas ideias livremente. Esse espaço que não era de preenchimento obrigatório foi utilizado por cerca de 300 agentes. Todo o material foi lido integralmente e organizado. Nele não houve homogeneidades, mas ênfases que aqui serão tratadas como estruturas de relevância e classificadas segundo os cinco indicadores propostos por Padilha ${ }^{12}$.

A importância metodológica deste estudo está numa premissa clássica das pesquisas qualitativas, segundo a qual, é fundamental dar destaque às expressões trazidas pelos sujeitos quando descrevem sua situação, para compreendê-las e, em seguida, interpretá-las dentro do contexto ${ }^{8,13,14}$.

\section{Análise dos indicadores de valorização dos policiais}

\section{Dignidade}

Dignidade corresponde ao respeito que a presença da instituição e do profissional impõe. Teoricamente não existem dúvidas sobre a importância do papel do policial civil ou militar. Profissão histórica criada entre os séculos XVII e XIX em vários países da Europa, a polícia se tornou uma peça-chave na governabilidade mundo afora, inclusive no Brasil. Vários autores têm estudado o período histórico ${ }^{15-17}$ no qual a Polícia Brasileira foi criada e as características europeias que a inspiraram. Santos ${ }^{17}$, por exemplo, discorre sobre o desenvolvimento do Estado Moderno, lembrando que sua lógica repousa sobre instrumentos de coesão e de coerção social e que a polícia foi criada para atuar na manutenção desse equilíbrio, embora lhe tenha sido destinada, como missão, o monopólio da violência física legítima em nome do Estado, substituindo a prática da justiça pelas próprias mãos.

A Constituição de 1988, no seu artigo 144, lembra que "A segurança pública, dever do Estado, direito e responsabilidade de todos, é exercida para a preservação da ordem pública e da incolumidade das pessoas e do patrimônio, através dos seguintes órgãos: polícia federal; polícia rodoviária federal; polícia ferroviária federal; polícia civil; polícia militar e corpos de bombeiros militares". Assim, está nas mãos das forças policiais a missão de proteger o livre exercício dos direitos e das liberdades, e de garantir a segurança do cidadão. O constituinte de 1988, reconhecendo a importância do papel da polícia na sociedade, o transformou em tema constitucional.
Desta forma, fica claro que às Corporações Policiais, formalmente, nunca faltou dignidade em seu papel estruturante e essencial de poder de Estado, uma dignidade prévia que investe as pessoas que desempenham tal papel ${ }^{7}$. Minayo et al. ${ }^{4,10}$ encontraram um dado interessante sobre as Corporações aqui estudadas: quase $75 \%$ do policiais do Estado do Rio de Janeiro (civis e militares) disseram que se lhes fosse dada a oportunidade de recomeçar hoje, escolheriam a mesma profissão. E, na análise das falas espontâneas, observa-se que, em geral, nas duas Corporações, o papel entranha a identidade profissional e social dos agentes. A maioria deles tem uma relação positiva com seu papel social e, mesmo em situação de desvantagem, consegue sentir-se integrada, valorizada e produtiva, constituindo uma categoria de pessoas teoricamente denominadas resilientes ${ }^{18}$.

No entanto, o reconhecimento desse status institucional não entranha as percepções de todos os membros das Corporações porque, mesmo quando determinados papéis sociais proveem as pessoas com oportunidades antecipadas, o melhor aproveitamento de suas potencialidades depende de atributos pessoais e da gestão corporativa $^{7}$. Nos estudos já citados ${ }^{4,10}$, além dos $25 \%$ que não escolheriam de novo a profissão se lhes fosse possível optar, mesmo a maioria que tem uma atitude positiva faz críticas contundentes às condições de trabalho e à forma de gestão. As duas citações a seguir são emblemáticas: uma ressalta a falta de reconhecimento social e, a outra, um profundo sentimento de desvalorização institucional:

A polícia é a latrina da sociedade, ninguém gosta, mas na hora de despejar seus anseios, mágoas, ira e culpar pelo flagelo social que vive, é na cabeça do policial que estes vomitam (Inspetor da Polícia Civil).

A Polícia é uma instituição acabada (...). Os políticos, os governantes, a população e instituições não-governamentais não apoiam e nem se interessam em ajudar, mesmo que seja para o bem comum. Em um país em que há sujeiras, sacanagem para todos os lados, a polícia militar é apenas uma engrenagem dessa podridão (Cabo da Polícia Militar).

Na voz de um cabo da polícia militar, a dignidade da função não se sustenta quando não há condições suficientes para exercê-la: "Um policial desprezado e desaparelhado gera descrédito e desrespeito da população, não só do cidadão de bem, mas também, do marginal da lei”. Embora, nos depoimentos espontâneos tenha havido fa- 
las positivas, o conjunto delas traduz um "sentimento de desvalorização", sugerindo a necessidade de formas de gestão que considerem cada um dos agentes e incluam a sociedade. Nesse particular é importante retomar a fala de Paixão e Beato Filho ${ }^{19}$ no estudo sobre "Crimes, vítimas e policiais". Esses autores ressaltam que chegou a hora da sociedade perceber as articulações positivas entre a polícia e a cidadania de todos os brasileiros e que, atuar nesse ponto faz parte do processo de democratização do país.

\section{Realização}

Segundo Padilha ${ }^{12}$ "realização" significa construir projetos profissionais e de vida, sem que haja comprometimento da saúde e da integridade física, moral e emocional do indivíduo. Esse autor observa que cada vez mais as pessoas concebem sua inserção institucional como forma de produzir melhorias para a comunidade, pois o orgulho de contribuir com a sociedade é um sentimento altamente motivador. Nesse sentido, as instituições que consideram seus profissionais como precioso capital social, investem neles.

Várias propostas são hoje implementadas pelas organizações para valorizar seus funcionários: oportunidades para aprimorar a educação formal ou para aprender uma segunda língua; treinamento de novas habilidades com recompensa pelo tempo de estudo; avaliação de desempenho com prêmios pelas boas ideias, boas práticas e, sobretudo, por inovações no processo de trabalho e nos meios de atuação; prêmios e menções frequentes aos melhores profissionais, votados e escolhidos pelos colegas de trabalho; plano de saúde e odontológico; seguro de vida; apoio de outras instituições parceiras como escolas de língua estrangeira, clínicas de psicoterapia, academias de ginástica, restaurantes, lojas, clubes e outros.

Ouvindo os policiais, são várias as questões acima tratadas que aparecem em suas falas: (1) a maioria refere que busca se aperfeiçoar, mas o faz por conta própria. Vários sugerem que seria importante criar cursos associados ao crescimento na carreira de forma a torná-la mais interessante; (2) muitos consideram que deveriam ter tempo para se aprimorar durante a jornada de trabalho e não fora do expediente, como geralmente ocorre, tirando-lhes o pouco tempo de lazer; (3) vários julgam importante a publicação de mais elogios nos Boletins Internos e não apenas notícias sobre punições, alterações nas leis e questões burocráticas; (4) diversos deles falam sobre a necessidade de treinamentos condizentes com a área de atuação, com visão aprimorada de cunho social e de cidadania e participação em congressos, simpósios e palestras, visando a trocas de experiências vividas com abordagens teóricas.

O sentido coletivo das falas sobre realização profissional ressalta a necessidade que os policiais sentem de ter um olhar mais abrangente sobre o país, como condição para servir melhor a sociedade. O sentimento de falta de reconhecimento institucional e de oportunidades para o crescimento pessoal e profissional, na expressão de um servidor "corrói por dentro o espírito de qualquer funcionário". Dois depoimentos, um mais resignado e um mais revoltado, mostram o quanto lhes causa mal o alheamento institucional e o obscurecimento dos indivíduos dentro das instituições.

Só na policia, [tenho] um total de 38 anos. [Nela entrei] aos 23 anos e não pensava no que o Estado faria por mim, mas no que de melhor eu poderia fazer para ele. Os anos se passaram, o fruto de toda árvore que crescia em relação à instituição foi se deteriorando, [como] podemos constatar nos nossos meios de comunicação: a verdadeira corrupção e o descaso com os seus integrantes. Fiz a minha parte, durmo e acordo sem qualquer tipo de preocupação, pois cumprir com dignidade [o meu dever] foi o meu maior merecimento como homem. Não tive envolvimento em qualquer situação ilícita ou que transgredisse disciplinarmente a minha posição. Se não fui promovido é que não tive o merecimento diante do sistema, mas com certeza me acho promovido em minha conduta. Hoje me sinto um cachorro policial, velho e desdentado e com certeza é o que os nossos [colegas] também sentem, sem oportunidades de subir na carreira, sem salário digno, sem nenhuma assistência médica (Inspetor da Polícia Civil).

Gostaria de estimar a minha revolta. (...) Hoje sou condenado, a não ser mais promovido, ficando parado na graduação de segundo-sargento. Assim como eu, existem na Polícia Militar mais companheiros nesta situação. Por não ter perspectiva de promoção dentro deste quadro, muitos já pediram transferência para a inatividade, mão de obra que a Polícia Militar está perdendo (Segundo Sargento da Polícia Militar).

Essas duas falas ressaltam uma espécie de obscuridade em que alguns funcionários vivem, talvez passando por várias chefias sem nunca terem sido notados. Infelizmente, faltou-lhes oportunidade de oferecer uma contribuição mais significativa. A questão da acomodação profissional - o contrário da realização - que se encontra particularmente entre os policiais de meia idade tem sido estudada. Brooks e Piquero ${ }^{20}$, por exem- 
plo, afirmam que o estresse surge, sobretudo, na metade da carreira do policial, e muitos apresentam doenças como problemas cardiovasculares, vários tipos de câncer, estresse cumulativo, depressão, insônia dentre outros, o que também está referido em Minayo et $\mathrm{al}^{4,10}$.

\section{Reconhecimento}

Esse terceiro indicador corresponde à inestimável sensação da pessoa de que seu trabalho é necessário e valioso ${ }^{12}$. Falta de reconhecimento é o elemento mais relevante nas falas dos policiais. Seus depoimentos começam, invariavelmente pela questão salarial, sendo numericamente a mais referida e qualitativamente a mais explicitada. A seguir, as principais referências abrangem precárias condições de trabalho e moradia, problemas de acesso aos serviços de saúde para si e suas famílias e um clamor por apoio institucional e psicológico.

Salários - Quando os especialistas em recursos humanos dizem que dinheiro não é tudo na valorização dos trabalhadores, logo a seguir acrescentam que cuidar bem de um profissional e reconhecer sua contribuição passa sim, por uma remuneração justa e atraente ${ }^{9,12}$. Em todas as falas espontâneas dos policiais a questão salarial aparece e seus argumentos estão a seguir reunidos:

O salário é considerado muito ruim quando comparado ao das Corporações de outros Estados; e porque é incompatível com a atividade de risco que eles exercem. Um dos participantes comenta: "a vida do policial é diferente de qualquer outra profissão. Ele a arrisca 24 horas por dia, em consequência precisa ter tranquilidade quanto às condições de vida e à capacidade de manter a família”.

Por ser muito baixo, o salário desestimula a produtividade, a dedicação e o empenho do servidor, prejudicando o resultado da segurança da população.

O salário ruim significa falta de reconhecimento profissional, o que se aguça por várias discrepâncias: pessoas com a mesma função igual são remuneradas desigualmente e promoções previstas em estatuto não são realizadas. Na Policia Militar, os agentes se referem também às grandes diferenças entre o soldo dos oficiais e o das praças; e na Polícia Civil, a defasagem entre a remuneração dos delegados e a dos outros agentes.

O salário ruim traz pior condição de vida pessoal, familiar e de saúde. Reagindo à fala dos governadores quando dizem que investem na Polícia, muitos citam que não é suficiente dar carros novos e armamentos tecnicamente atualiza- dos se seus contracheques ficam cada vez mais minguados e não conseguem uma vida digna para suas famílias.

Frente ao salário ruim, dizem os agentes, a questão não se resolve com alguns mecanismos atualmente utilizados que visam a melhorar a produtividade no trabalho, pois a recompensa é esporádica e não se incorpora a sua remuneração. Emitem fortes críticas às políticas salariais feitas à base de muito escalonamento nas reposições do soldo e nas gratificações que entram e saem do contracheque. Segundo vários participantes, elas são um símbolo da falta de reconhecimento.

A política salarial carece de um plano de carreira e de promoções, o que não ocorre por descontinuidade dos projetos e das propostas institucionais, sempre sob a dependência dos chefes de governo de plantão;

Por fim, o salário insuficiente leva à necessidade de buscar outro emprego, o que muitos consideram uma péssima alternativa. Um dos policiais civis comentou:

É falácia achar que se os policiais ganharem melhor-um salário que permita manter a família - vão continuar fazendo "bico". Infelizmente, a maioria atua assim, em busca de complementações muito pequenas, insuficientes e até humilhantes. $\mathrm{Na}$ verdade, a maioria aceitaria dar um horário integral na polícia se for bem remunerada, pois em geral, quem tem empresas e ganha muito por fora das Corporações são os que mais podem como é o caso dos delegados ou dos oficiais e não dos que ganham menos como nós.

Plano de moradia - Quando se refere à valorização profissional, a maioria coloca como um dos pontos principais, sua possibilidade de oferecer conforto à família e as condições habitacionais: (1) muitos ressaltam que vivem em áreas de risco, porque é o que o salário permite; (2) vários falam das distâncias entre os locais em que servem e suas casas; (3) outros, sugerem, veementemente, que o Estado lhes propicie um plano de financiamento e subsídios, não para construir uma cidade da polícia onde se segregariam da sociedade, mas para que possam optar sobre onde morar. Na verdade, vários policiais falam de um conjunto de condições que para eles significa reconhecimento do estado e da sociedade, o que se expressa no depoimento a seguir:

Subsídios para aquisição de moradias, transportes, educação, entretenimento, alimentação de qualidade. Viabilidade de ascensão profissional diferente das atuais que premiam o policial violento, truculento e homicida. Tem que haver seminá- 
rios, cursos, palestras, reciclagem e acompanhamento do desempenho profissional (Capitão da Policial Militar)

Plano de Saúde e Odontológico - Embora seja um ponto polêmico nas instâncias institucionais, quando perguntados sobre o que deveria ser feito para sua valorização, a maior parte dos policiais sugere que lhes seja propiciado um plano de saúde pessoal e para a família. No caso dos Policiais Militares, os que mais demandam são os que atuam no interior, embora os da Capital e da Baixada se queixam do tempo muito demorado para atender a suas necessidades de consultas e de outros procedimentos mais complexos. Os Policiais Civis se ressentem da falta absoluta de estrutura para atendimento de sua saúde. Alguns mais jovens comentam que suas famílias de origem arcam com as despesas para que tenham plano de saúde.

Trabalho numa unidade policial do interior, onde não temos acesso a nenhuma assistência à saúde pessoal ou familiar da polícia civil! Não é justo que com salários tão baixos ainda tenhamos que pagar do próprio bolso, consultas, exames e cirurgias! [Inspetor de Polícia do interior]

Perguntem à cúpula da segurança pública, o seguinte: a) se fora os exames admissionais os policiais fazem check-up anuais. Pelo menos eu e todos com quem converso, nunca fizemos; b) perguntem se o setor médico das polícias tem o PPP (Perfil Profissiográfico Profissional) de cada policial, garanto e aposto que não; c) perguntem se existe algum programa específico de saúde para policiais com diabetes, cardiovascular, drogas, apneia do sono e outros; d) perguntem se existe alguma preocupação médica com os policiais que tiram plantões e as doenças que adquirem ao longo dos anos; e) por fim, perguntem pelo Hospital da Policia Civil, que chega a ser vergonhoso e deprimente e que ainda está de pé, em razão de uns poucos abnegados que tentam mantê-lo (Inspetor da Policia Civil).

Melhoria nas condições de trabalho Nos livros Missão Investigar e Missão Prevenir e Proteger ${ }^{4,10}$, as condições de trabalho dos policiais são tratadas em profundidade. Aqui, apenas se citam algumas questões sobre as melhorias que os policiais sugerem em suas falas. Toma-se como exemplo o que escreveram dois policiais civis que trabalham em delegacias da Baixada:

Em 19 anos de trabalho só pude tirar férias cinco vezes, pois não tem quem me substitua. Mas além de férias, para a valorização do policial é preciso: melhorar as condições salariais; melhorar as condições de apoio ao serviço policial; melhorar as condições de apoio ao policial; ter um plano de saúde para o policial e família; e melhorar as análises quanto às promoções na carreira.

Tentarei em poucas linhas dizer o que ocorre sem mascarar ou mentir: trabalho nesta instituição acerca de vinte anos aproximadamente, com mais de 70\% deste tempo em uma delegacia da Baixada Fluminense no serviço de plantão em escala de $24 \times 72$ horas. O trabalho é árduo, mas conta atualmente com o mesmo efetivo de plantão do tempo em que cheguei para o meu primeiro serviço nos anos de 1990. Apenas trocando os personagens, ou seja, além deste signatário, apenas mais um homem para completar a chamada equipe de plantão; estes dois homens são responsáveis pela confecção do RO; encaminhamento das partes para os órgãos (IML); local de homicídio, confecção de flagrantes e ainda transporte de presos. Essa é a rotina! Embora o plantão de $24 \times 72$ horas seria até compensador se este período de descanso fosse utilizado para tal, mas não o é, por ter sempre este servidor que ir para uma atividade paralela (bico), em uma segurança para completar a renda de minha família.

Os dois depoimentos acima tocam fundo na questão da gestão tema da fala de um capitão da polícia militar que ressalta a importância de uma renovação das Corporações de modo a tornálas condizentes com o papel social que exercem e o momento histórico que vivenciam:

Deveria haver uma avaliação nas instituições policiais no intuito de rever práticas e procedimentos que incidam sobre condições de trabalho, preparação contínua do policial e clima organizacional. Também deveria haver uma politica de Estado no sentido de aumentar a eficiência das instituições policiais, pois faltam equipamentos; a quantidade de funcionários é insuficiente; $e$ os horários de trabalho são incompativeis com as normas trabalhistas.

\section{Segurança}

O quarto indicador aqui tratado é a segurança profissional segundo a qual nenhuma pessoa pode se achar valorizado caso se sinta insegura em relação ao serviço que presta ${ }^{12}$. Cuidando da segurança pública, os policiais não estão descobertos quando ao conceito de segurança pessoal, noção que deriva do mundo do trabalho e tem um sentido ordenador dos direitos dos funcionários. Representa o conjunto de normas destinadas a prevenir acidentes e a proteger o trabalhador, eliminando condições inseguras ou perigosas de trabalho. Esse conceito é importante para se pensar que os policiais não são máquinas de produzir segurança e sim servidores pú- 
blicos, também protegidos pela Constituição, que lhes garante integridade física e mental no desempenho de suas atividades.

Na discussão da segurança do policial como trabalhador, as falas abrangem: (1) as situações de risco que vivenciam e nas quais muitos se acidentam, lesionam-se ou morrem, em proporções muito mais elevadas do que a população civil $^{21}$; (2) as dificuldades que enfrentam para realizar sua missão em ambientes socialmente conflagrados; (3) as condições adversas nas quais frequentemente exercem jornadas longas e extenuantes, (4) a insuficiência de servidores para a quantidade de serviço, (5) equipamentos de trabalho e de proteção pessoal frequentemente inadequados, (6) sobretudo, no caso dos Policiais Civis, escassos períodos de férias.

O apoio institucional aos serviços e o apoio psicológico aos policiais foi também tratado como um tema de segurança no trabalho, embora de forma bastante controversa. Ao mesmo tempo em que muitos se ressentem de ficar desamparados frente às difíceis situações que enfrentam, outros dizem que não se abrem para ajuda e a desdenham, por receio de serem considerados fracos pelos colegas. Um dos agentes chegou a dizer: "precisamos de qualquer tipo de ajuda”. Um policial militar comentou que em seu batalhão, quando alguém passa por alguma situação difícil procura apoio no capelão, pois julga que está falando com Deus e assim ninguém tem motivos para questioná-lo. Essa é uma situação bastante anacrônica, pois, retorna a solução dos casos ao estágio précientífico, quando os problemas individuais e coletivos eram atribuição de instâncias religiosas.

Embora não utilizando a palavra, muitos policiais se referem a intenso sofrimento psíquico, como na fala de alguns cabos e soldados de um batalhão situado em área de altos índices de criminalidade. Vários discorrem, emocionados, sobre a banalização e o tratamento corriqueiro dos casos de morte dos companheiros de serviço. Por viverem, frequentemente, situações de elevado risco, esses agentes falaram de uma experiência muito particular de proximidade com a morte que se reatualiza a cada dia.

O argumento de que os policiais são profissionais preparados para o confronto frequentemente justifica a ausência de um suporte especializado. $\mathrm{Na}$ verdade, essa falta de apoio denota o pouco cuidado do Estado com o seu capital humano e a falta de consciência da sociedade sobre a importância de um dos pilares da democracia moderna. Nesse sentido, é muito significativo o depoimento a seguir que mostra o sofrimento e os temores de muitos agentes da Polícia Civil em relação a como lidar com os problemas que enfrentam no cotidiano e as repercussões que isso traz para sua vida familiar:

Outro fator importante é que desde que vim para essa delegacia, mesmo sendo uma delegacia de pequeno porte o estresse continua o mesmo. O problema está nas dificuldades de gerenciamento, de conflitos na área de violência doméstica e familiar, no sentimento de injustiça que nos acaba afetando as emoções, pois não somos capacitados para lidar com esses problemas, acabamos por sofrer influência psíquica dos problemas dos outros, que trazem à tona os nossos próprios, que também não sabemos como gerenciar. A raiva, o ódio, a revolta, a indignação ficam a flor da pele e se não vigiarmos acabamos por despejá-los nas partes envolvidas. A tensão é constante. Não há como dar um tratamento igual aos policiais que trabalham longe dos problemas sociais. Penso que o tratamento ao pessoal do plantão nas delegacias tem que ser especializado e melhor gratificado.

Corroborando o depoimento acima, estudos com policiais americanos e nacionais destacam vários aspectos que causam sofrimento psíquico nos policiais, como a falta de reconhecimento por parte dos superiores e da população, o medo de obsolescência frente às mudanças tecnológicas, as poucas perspectivas de promoção e crescimento na carreira, as dificuldades para lidar com a população e o fato de terem que tomar decisões que afetam a vida e a integridade dos outros, em confrontos. Muitos autores realçam o papel negativo da insatisfação, da ansiedade, da falta de comunicação e da depressão na vida dos policiais $^{22,23}$. Sobretudo, a falta de possibilidade de expressar o sofrimento ${ }^{24,25}$ acaba fazendo sinergia com várias outras formas de adoecimento: problemas gastrintestinais, disfunções cardíacas, insônia, irritação, dentre outros, têm sido apontados como consequências de estressores organizacionais vinculados a reações pessoais frente a condições adversas de trabalho ${ }^{22}$.

Em estudos anteriores de Minayo et al. ${ }^{4,23}$ foram realizadas análises fatoriais sobre maior vulnerabilidade ao risco entre policiais mostrou alta significância para as seguintes questões: falta de lazer, exercício de atividades para as quais os profissionais não estão preparados, trabalho sem descanso e estresse intenso.

Em resumo, também nas questões se segurança enquanto direito, faz-se necessário investimento das Corporações Policiais. Mas esse cuidado não pode se limitar à proteção interna, pois estudos de Souza e Minayo ${ }^{21}$ mostram que poli- 
ciais fora da jornada de trabalho se lesionam e morrem mais, inclusive em confrontos com os delinquentes que os reconhecem com distintivos das Corporações ou não. Esse dado reforça a importância do apoio governamental para que, em suas moradias, os policiais e suas famílias se sintam seguros.

Perspectiva promissora - $\mathrm{O}$ último indicador de valorização profissional é o que se refere à perspectiva promissora em relação ao futuro. Corresponde à probabilidade de crescimento na carreira, na remuneração, nos conhecimentos, nas habilidades e na capacidade profissional de enfrentar situações que coloquem em xeque seu talento pessoal. Se o exercício da profissão não oferece perspectiva de futuro, dizem os profissionais de recursos humanos, não vale a pena continuar investindo nele.

A concluir sobre o conjunto de questões já tratadas, as carreiras tanto dos policiais civis como dos militares têm uma rigidez bastante grande, o que os leva à acomodação, à descrença e a pouca expectativa de futuro. Na fala de dois policiais civis esse quadro é retratado mostrando seus esforços em investimentos próprios e a falta de resposta institucional.

Por conta própria eu fiz vários cursos na área de segurança, inclusive um ministrado por especialistas israelenses que são considerados entre os melhores do mundo. Fiz um curso de especialização de gestão do trabalho. Tudo o que fiz e faço é por minha conta, por internet ou nos finais de semana. Mas nem busquei os certificados porque sei que não vai valer de nada. Se eu quiser ter alguma coisa na vida vou ter que fazer bico, me humilhar ou me corromper (Inspetor da Polícia Civil).

Não há motivação na policia civil, não há estímulo, não há uma alegria! Há um hiato entre os superiores e os agentes, não há diálogo. Os superiores se arrogam o direito de patrões, ficando divorciados dos subordinados. Há necessidade urgente de um plano de carreira, de um aumento salarial que contemple a todos. Até no pagamento há diferença incomensurável entre delegados e agentes (Inspetor da Polícia Civil).

Conforme os melhores manuais de recursos humanos, é necessário haver uma política de valorização de talentos, com práticas continuadas de feedback que ajude a pessoa e os grupos a melhorar seu desempenho e a atingir seus objetivos. As práticas justas de reconhecimento geralmente fazem do ambiente um bom lugar para trabalhar, o que facilita a retenção de talentos.

\section{Conclusões}

O sentido deste estudo é a certeza de que o êxito das organizações - e de organizações tão importantes socialmente como é o caso das Corporações Policiais - depende de, além de selecionar os melhores talentos, saber mantê-los sempre motivados.

O conjunto de questões tratadas poderia ser resumido com uma frase de Gabriele: "para a valorização profissional basta que a instituição perceba que atrás de seu trabalho bem feito há um ser humano que precisa de reconhecimento, de certeza quanto ao caminho a seguir, para poder confiar e responder adequadamente" ${ }^{\text {. }}$ Quando se fala das Corporações Policiais, porém, as soluções são complexas, pois estão em jogo duas categorias com um número elevado de servidores, com estatutos e funções bastante rígidas e dependentes do poder do Estado. Setores empresariais progressistas utilizam certos instrumentos para incentivar os trabalhadores como concursos internos que acabam dando vez aos que se aprimoram; prêmios e recompensas associados a inovações e à dedicação profissional. Mas, esses dispositivos costumam ser difíceis de serem implantados no setor público, pois não constituem medidas que valorizem e abranjam as diferentes atividades e locais de inserção. Portanto, a valorização profissional dentro das Corporações Policiais precisa ser pensada como uma intervenção complexa e peculiar, que produza várias mudanças concomitantes.

Apesar das dificuldades, muitas iniciativas poderiam ser introduzidas, sobretudo as que fossem orientadas para a coesão corporativa, segurança e qualidade de vida dos policiais e suas famílias. Para isso também seria necessário institucionalizar e dar continuidade a práticas que permitissem a expressão de cada um dos servidores com sua capacidade e experiência. As soluções para valorização profissional têm que surgir de dentro, embora devam sempre ser acompanhadas do arejamento que traz a colaboração de outras instituições. Assegurar avaliação externa de tempos em tempos, a partir de um planejamento participativo, propicia um sentido de objetividade e crítica, pilares de qualquer efetividade na gestão.

Por todos os aspectos citados, ressalta-se que este artigo não constitui uma proposta para as Corporações. Ele é apenas e tão só, uma leitura compreensiva e interpretativa dos escritos que os policiais confiaram aos pesquisadores. Ao governo do Estado, representado pela Secretaria 
de Segurança Pública e aos gestores da Polícia Civil e da Polícia Militar cabe decidir o que podem fazer para valorizar os servidores.

O momento atual é uma janela privilegiada de oportunidades, frente às mudanças positivas já conseguidas no trato com os delinquentes no Estado e na percepção da importância da segurança pública por parte da sociedade. O que parecia impossível aconteceu nos territórios das favelas dominados por traficantes de drogas, hoje devolvidos à população. Sem dúvida, observando-se o imenso esforço que o setor tem sido capaz de realizar, é viável pensar em mudanças institucionais com a contribuição de todos os agentes, pois a agudeza, a seriedade de sua reflexão e a adesão a suas Corporações refletem na riqueza e na contundência dos depoimentos que deram origem a este trabalho. Embora, não se possa esconder que em muitos policiais existe uma elevada dose de pessimismo e de descrença.

Um aspecto relevante a ser ponderado é que os policiais do Rio de Janeiro estão cada vez mais es- colarizados: mais de 70\% dos civis e mais de 30\% dos militares ${ }^{4,10}$ têm curso superior, sendo a maioria bastante jovem. $\mathrm{O}$ crescimento dessa massa crítica é fundamental e não pode ser menosprezada no esforço de valorização institucional e profissional. Segundo um capitão da policial militar: "notoriedade e reconhecimento são fundamentais para que os profissionais parem de criticar e passem a agir a favor de um país mais justo, digno, menos corrupto, exigindo, junto com os outros cidadãos, uma reforma política verdadeira”.

Por fim, pensando no grande sofrimento que significa a falta de reconhecimento e a imagem negativa que os policiais percebem por parte da sociedade, caberia investir num marketing social bem pensado, com ajuda da mídia e de formadores de opinião. Esse marketing social, que não deve esconder as denúncias cotidianas de corrupção, contribuirá para que o policial se sinta prestigiado e tenha a população a seu lado, oferecendo-lhe reconhecimento pelo eminente e indelegável serviço que presta. 


\section{Referências}

1. Melo MTL. Programas oficiais para formação de professores de ensino básico. Educação \& Sociedade 1999; 20(68):46-60.

2. Stacciarini JMR, Troccoli BT. O estresse na atividade ocupacional do enfermeiro. Rev. Latino-Am. Enfermagem 2001; 9(2):17-25.

3. Meirelles DS. O conceito de serviços. Rev Economia Política 2006; 26(1):119-136.

4. Minayo MCS, Souza ER, Constantino P, organizadoras. Missão prevenir e proteger: condições de trabalho, de saúde e de vida dos policiais militares do Rio de Janeiro. Rio de Janeiro: Editora Fiocruz; 2008.

5. Wolfensberger W, Thomas S. An analysis of the cient role from a social role valorization perspective. The International Social Role Valorization Journal 1994; 1(1):3-8.

6. Lemay R. Good intention and hard work is not enough. The International Social Role Valorization Journal 2001; 4(1-2):94-97.

7. Lemay, Raymond. Problems of discourse concerning roles. The International Social Social Role Valorization Journal 1994; 1(1):45-46.

8. Dejours C. O fator humano. Rio de Janeiro: Editora FGV; 1997

9. Gabriele ALB. É o momento de valorização profissional. ABEP 2001; 24(88):1-2.

10. Minayo MCS, Souza ERS, organizadoras. Missão Investigar: entre o ideal e a realidade de ser policial. Rio de Janeiro: Editora Garamond; 2003.

11. Minayo MCS, Souza ER, Constantino P. Riscos percebidos e vitimização de policiais civis e militares na (in)segurança pública. Cad Saude Publica 2007; 23(11):2767-2779.

12. Padilha E. Valorização Profissional. [artigo na Internet]2011; [cerca de 12 p]. [acessado 2011 jun 27]. [cerca de 6 p.]. Disponível em: http://www. eniopadilha.com.br/eventos_documentos/200434_10_eniopadilha_valoriza_profiss.pdf.

13. Schutz A. Fenomenologia e relações sociais: textos escolhidos. Rio de Janeiro: Zahar, 1987.

14. Minayo MCS. O desafio do conhecimento: pesquisa qualitativa em saúde. 12a Edição. São Paulo: Hucitec; 2010.

15. Elias N. O processo civilizador. Rio de Janeiro: Jorge Zahar Editora:1994.
16. Foucault M. Vigiar e punir. Petrópolis: Editora Vozes; 1989.

17. Santos JVT. A arma e a flor: formação da organização policial, consenso e violência. Tempo Social 1997; 9(1):155-167.

18. Assis SG, Pesce RP, Avanci JQ. Resiliência: enfatizando a proteção dos adolescentes. Porto Alegre; Artmed; 2006.

19. Paixão AL, Beato Filho CC. Crimes, vítimas e policiais. Tempo social 1997; 9(1):233-248.

20. Brooks LW, Piquero NL. Police Stress: Does Department Size Matter? Policing: An International Journal of Police Strategies and Management 1998; 21(4):600-617.

21. Souza ER, Minayo MCS. Policial, risco como profissão: morbimortalidade vinculada ao trabalho. Cien Saude Colet 2005; 10(4):917-928.

22. Kelley TM. Mental health and prospective police professionals. Policing: an International Journal of Police Strategies \& Management 2005; 28(1):6-29.

23. Minayo MCS, Souza ER, Assis SG, Oliveira RVC. Impacto das atividades profissionais na saúde física e mental dos policiais civis e militares do Rio de Janeiro (RJ, Brasil). Cien Saude Colet 2011; 16(4): 2199-2209.

24. Brant LC, Minayo-Gomez C. The transformation process of suffering into illness: from the birth of the clinic to the psychodynamic work. Cien Saude Colet 2004; 9(1):213-2018.

25. Brant LC, Minayo-Gomez C. A temática do sofrimento nos estudos sobre trabalho e saúde. In: Minayo-Gomes C, Machado JMH, Pena PGL, organizadores. Saúde do trabalhador na sociedade brasileira contemporânea. Rio de Janeiro: Editora Fiocruz; 2011. p. 385-410.

Artigo apresentado em 22/11/2011

Aprovado em 29/01/2012

Versão final apresentada em 31/01/2012 